\title{
WETTING AND DRYING RESISTANCE OF LIME-STABILIZED EXPANSIVE SOILS MODIFIED WITH NANO-ALUMINA
}

Scientific paper

(Received: 13 May 2020; accepted: 22 February 2021)

\author{
Jijo James \\ SSN College of Engineering, Department of Civil Engineering, Associate Professor \\ Corresponding author: ijijojssn.edu.in \\ Sivapriya, S.V. \\ SSN College of Engineering, Department of Civil Engineering, Associate Professor \\ Sajid Ali \\ SSN College of Engineering, Department of Civil Engineering, Undergraduate \\ Madhu, T.R. \\ SSN College of Engineering, Department of Civil Engineering, Undergraduate \\ Basudev Singh \\ SSN College of Engineering, Department of Civil Engineering, Undergraduate
}

\begin{abstract}
Weak soil at construction sites necessitates ground improvement. Chemical stabilization is typically carried out using either lime or cement. The primary objective of this study was to assess the strength and durability of lime-stabilized soils modified with nano-alumina (NA). This study adopted the scientifically established initial consumption of lime (ICL) content for soil stabilization. In addition, nano-alumina was added in varying percentages as an auxiliary additive. It was observed that $0.5 \%$ of nano-alumina was optimal with respect to the ICL for maximizing the soil stabilization. The stabilized soils were cured for $0,7,14$, and 28 days. Post-curing testing revealed that the strength increased sixfold for the optimal combination, compared with the virgin soil. To understand the durability behavior of the optimal combination, the stabilized soil specimens were subjected to wetting and drying cycles after 28 days of curing. The optimal combination was nearly as durable as that of the lime-stabilized soil subjected to five cycles of wetting and drying.
\end{abstract}

Keywords: Expansive soil; lime; unconfined compressive strength; nano- alumina; durability; wetting-drying. 


\section{INTRODUCTION}

Expansive soils have been noted all over the world, owing to their volume instability and consequent problems at constructed facilities, especially in the context of lightly loaded infrastructure systems, such as road pavements. Lime stabilization remains the preferred method for mitigating the expansive nature of such swelling soils. India has a very large landmass covered in expansive soils. Recently, several studies have focused on the use of auxiliary additives for soil stabilization. The considered additives have mostly been industrial and/or agricultural solid wastes. However, some researchers have focused on an entirely novel approach to soil stabilization, using nanomaterials (NMs). An NM can be defined as a physical substance with at least one dimension in the 1-100 nm range. NMs can be classified into fullerenes and nanoparticles. Fullerenes are carbon allotropes, which are conceptually graphene sheets rolled into tubes or spheres. Nanoparticles, on the other hand, are liquids or solids with particle sizes in the 1-100 nm range. Nanotechnology and its applications in civil engineering have grown rapidly in recent years. NMs have been also considered for soil stabilization. Ugwu et al. [1] used an organosilane NM as a preventative engineering solution for highway infrastructure failures. Bahmani et al. [2] investigated the stabilization of residual soil with cement and nano-silica (NS). Changizi and Haddad [3] studied clay soil stabilized with NS and reinforced with recycled polyester fibers. Correia et al. [4] explored the effects of multiwalled carbon nanotubes (MWCNTs) on cement-stabilized clay soil. Nikookar et al. [5] attempted to stabilize a silty soil using a nano-clay. Moradi and Seyedi [6] examined the delivery of colloidal NS for the stabilization of liquefiable silty sand. Correia and Rasteiro [7] evaluated the stabilization potential of MWCNTs and cement on clay soil. Wang et al. [8] analyzed the reinforcement mechanism of cement-stabilized soil amended with nano-CaO. Majeed and Taha [9] studied the effect of different NMs, such as nano-clay, nano-copper, and nano-MgO, on the geotechnical properties of Penang soft soil. Choobbasti et al. [10] explored the potential of NS for modification of cement-stabilized sandy soil. Alireza et al. [11] explored the use of NS modification in the lime stabilization of Boodian weak soil from Iran. Shahin et al. [12] reviewed various NMs used in the stabilization of soil, including NS and nano-clay, among a few other lesserused NMs. Nohani and Alimakan [13] examined the effect of nano-clay on the geotechnical properties of clay. The above survey suggests that recently, significant attention has been given to NMs, especially nanoparticles, rather than fullerenes, for soil stabilization. The most commonly adopted NM in combination with a stabilizer, such as cement, is NS. Silica is a pozzolanic material, and many studies have focused on its nano-level applications. However, the same level of investigative depth has not been accorded to other pozzolanic materials, such as alumina. Moreover, only a few studies considered the durability performance of NMs for soil stabilization. The novelty of the present study is its use of Nano Alumina (NA) as an auxiliary additive, instead of the more commonly adopted NS. Hence, this study focused on using NA in combination with lime for stabilization of expansive soils, while the soils' durability performance was also evaluated in response to alternate cycles of wetting and drying.

\section{MATERIALS AND METHODS}

The various materials used in this investigation were the expansive soil, industrial-grade hydrated lime, and NA. Lime acted as a primary stabilizer, whereas NA was used as anauxiliary additive for modifying the lime stabilization process.

\subsection{Soil}

The soil samples in the present study were sourced from near Thaiyur Lake near Kalavakkam, Tamil Nadu, India. On visual examination, the soil samples were dark gray to black in color, and were extremely hard in the dry state. Cutting wetted soil revealed a shiny surface, indicating the presence of fine clay in the soil samples. The soil samples were prepared following the BIS code IS 2720 Part 5 [14], and their geotechnical properties were characterized in a laboratory based on various parts of the BIS code IS2720; these properties and their values are listed in Table 1.

\section{Table 1 Geotechnical Properties of the Soil Samples}

\begin{tabular}{lc}
\hline Property & Value \\
\hline Liquid Limit [14] & $75.8 \%$ \\
\hline
\end{tabular}

James, J, Sivapriya, S V, Ali, S, Madhu T R, Singh, B 


\begin{tabular}{lc}
\hline Plastic Limit [14] & $23.5 \%$ \\
\hline Plasticity Index & 52.3 \\
\hline Shrinkage Limit [15] & $11.2 \%$ \\
\hline Specific Gravity [16] & 2.76 \\
\hline \% Gravel [17] & 0 \\
\hline$\%$ Sand [17] & 2.9 \\
\hline$\%$ Silt [17] & 28.4 \\
\hline \% Clay [17] & 68.7 \\
\hline Maximum Dry Density [18] & $13.09 \mathrm{kN} / \mathrm{m}^{3}$ \\
\hline Optimum Moisture Content [18] & $28.2 \%$ \\
\hline Unconfined Compression Strength [19] & $102.2 \mathrm{kPa}$ \\
\hline Classification [20] & $\mathrm{CH}$ \\
\hline
\end{tabular}

\subsection{Additives}

High-quality industrial-grade hydrated lime sourced from M/s Shiyal Chemicals, Chennai, India, was used in the present study. High-quality industrial-grade lime ensured the stabilizer's composition uniformity, thereby reducing variations in the test results. The chemical composition of lime obtained from M/s. Shiyal Chemicals, as evaluated in a previous study [21] using the X-ray fluorescence method, is listed in Table 2. The nano-sized alumina powder was sourced from M/s. Astraa Chemicals, Chennai, India; this powder is a white powder, very similar to lime in appearance. The specific gravity of NA was determined in a laboratory, based on IS2720 Part 3 [16], and was found to be 3.25 . Figure 1 shows the materials that were used in this study.

Table 2 Chemical Composition of Lime in \% [21]

\begin{tabular}{lccccccccccc}
\hline Oxide & $\mathrm{SiO}_{2}$ & $\mathrm{Al}_{2} \mathrm{O}_{3}$ & $\mathrm{CaO}$ & $\mathrm{Fe}_{2} \mathrm{O}_{3}$ & $\mathrm{~K}_{2} \mathrm{O}$ & $\mathrm{MgO}$ & $\mathrm{MnO}$ & $\mathrm{Na}_{2} \mathrm{O}$ & $\mathrm{P}_{2} \mathrm{O}_{5}$ & $\mathrm{TiO}_{2}$ & $\mathrm{SO}_{3}$ \\
\hline Lime & 4.73 & 0.38 & 81.05 & 0.08 & 0.00 & 3.22 & 0.00 & 799 & 0.18 & 0.05 & 2.33 \\
\hline
\end{tabular}

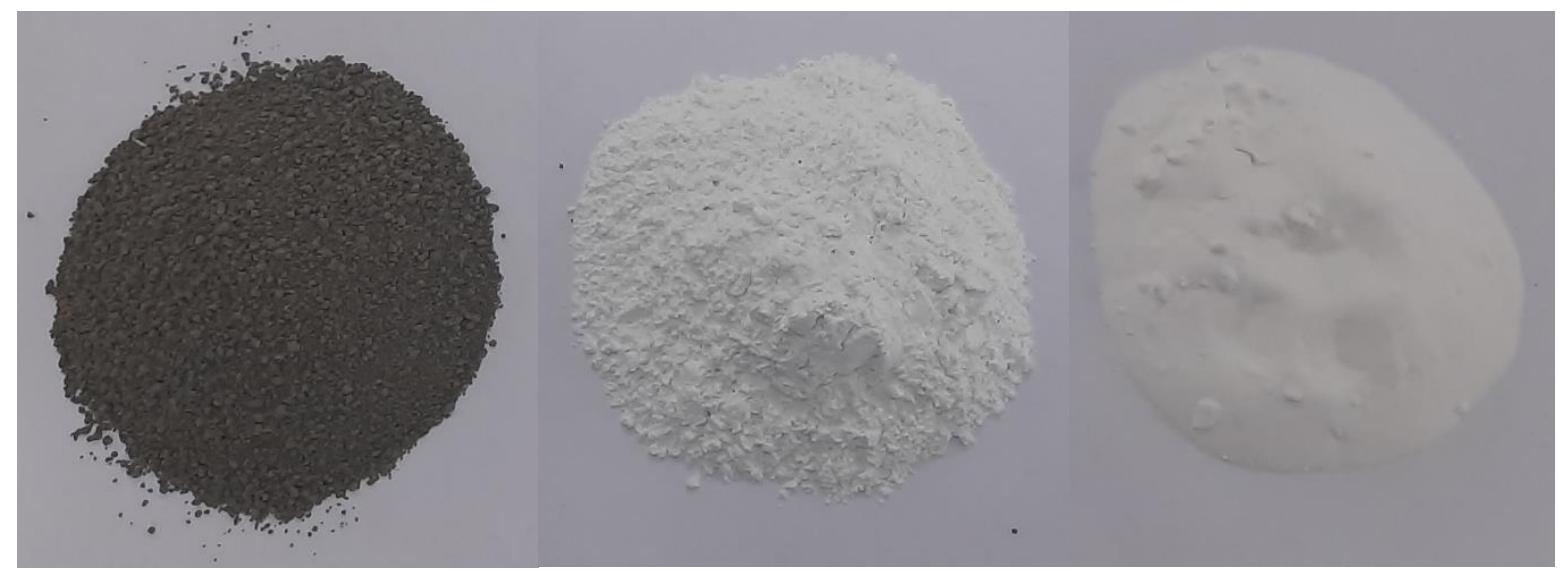

Figure 1 Materials Used: Soil, Lime, and NA (In the Order of Appearance)

\subsection{Methods}

First, soil samples were prepared and their geotechnical properties were characterized. The soil samples were airdried at room temperature, crushed, and pulverized, for breaking down large lumps. The soil samples were then sieved through the requisite sieves recommended for different tests, as recommended by the BIS code IS 2720 for geotechnical characterization. The soil samples were then classified based on the properties that were determined using the BIS code IS 1498 [20]. The additives were not processed using any specific preparatory methods, and were used as supplied by the manufacturers. The minimum lime content required for modifying the soil properties, known as the initial consumption of lime (ICL), was determined by the Eades and Grim pH test [22], following the 
ASTM code D6276 [23]. Along with this lime content, NA at different percentage levels were used as an auxiliary additive for modifying the lime stabilization process. This was done by preparing cylindrical specimens with dimensions of $38 \mathrm{~mm} \times 76 \mathrm{~mm}$; the specimens were of soil amended with lime at its maximum dry density and optimum moisture content, obtained from the mini compaction test. The calculated required quantity of soil for achieving the dry density was manually mixed with weighed dosages of lime and NA under dry conditions. After achieving a uniform dry mix, a calculated quantity of water was added and mixed manually to achieve a wet mix. Three specimens were prepared for each combination of lime and NA; the prepared specimens were cured for different time durations ( 2 hours, 7,14 , and 28 days) in a sealed polythene cover to prevent loss of moisture, at room temperature $\left(28^{\circ} \mathrm{C}+/-2{ }^{\circ} \mathrm{C}\right)$. A detailed description of the procedure for preparing unconfined compression strength (UCS) specimens can be found in the literature [24]. After curing, each specimen was removed from its polythene cover and strained axially in a $40-\mathrm{kN}$-loading frame at a rate of $1.25 \mathrm{~mm} / \mathrm{min}$ until failure. The combination with maximum strength was identified as the one corresponding to the optimal NA dosage. Next, for the configuration with the optimal NA dosage, durability was assessed and compared with that of the pure limestabilized soil, by subjecting prepared cylindrical specimens with dimensions of $38 \mathrm{~mm} \times 76 \mathrm{~mm}$ to alternate cycles of wetting and drying after 28 days of curing. The specimens were allowed to wet for $24 \mathrm{~h}$, after which the specimens were removed and allowed to dry in open air at a temperature of $28{ }^{\circ} \mathrm{C}+/-2^{\circ} \mathrm{C}$ for $24 \mathrm{~h}$. This constituted one cycle of wetting and drying [25]. In the case of lime-stabilized soil specimens, direct immersion in water may result in crumbling of the specimens. Hence, a simulation of wetting and drying was performed by preparing a bed of cotton and soaking it completely in water, followed by arrangement of the specimens on the soaked bed. This was followed by wrapping the specimens with another roll of cotton, ensuring that the cotton roll completely covered the surface of the specimens. The top wrapping of the cotton roll was then completely wetted. Care was taken to ensure that the cotton bed and wrapping were completely soaked wet throughout the duration of the wetting cycle. A similar procedure was reported in the literature [26]. Figure 2 shows the specimens subjected to wetting. The specimens were subjected to three and five cycles of wetting and drying. Three specimens were prepared for the control as well as combination of lime and optimal NA. Following the wetting and drying cycles, the specimens were subjected to axial straining at $1.25 \mathrm{~mm} / \mathrm{min}$, until failure.

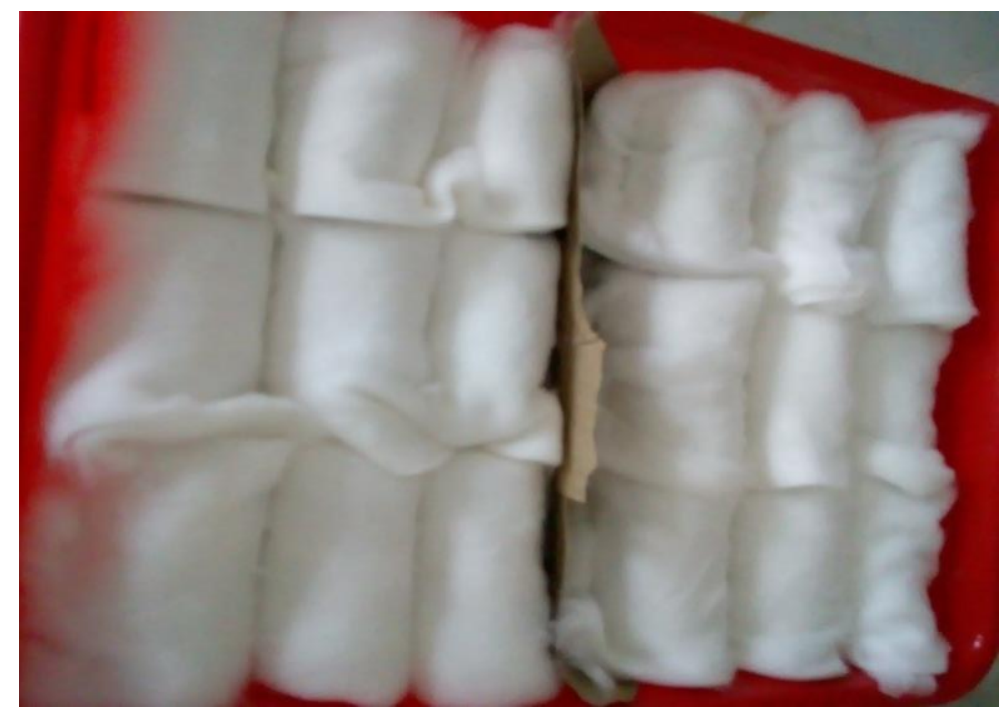

Figure 2 Specimens Subjected to Wetting Cycle for 24 hours

\section{RESULTS AND DISCUSSION}

This section discusses the study results regarding the effect of NA on the stabilization potential of lime and its durability. 


\subsection{Determination of ICL}

The ICL for the studied soil samples was determined using the Eades and Grim pH test following the ASTM code D6276 [23]. Figure 3 shows the variation in $\mathrm{pH}$ with the lime content, as determined from the $\mathrm{pH}$ test. ICL is defined as the minimum lime content required for increasing the soil $\mathrm{pH}$ to 12.4. This is the minimum lime content required for modifying the soil properties and is also known as the lime modification optimum. Based on this, from Figure 3 , it can be inferred that the ICL required for modifying the soil properties of the studied soil samples is $4.5 \%$. Thus, the studied soil samples were modified with at least $4.5 \%$ lime for improving their properties. This was followed by admixing the stabilization mixture with varying quantities of NA for studying its influence on the strength of the stabilized samples.

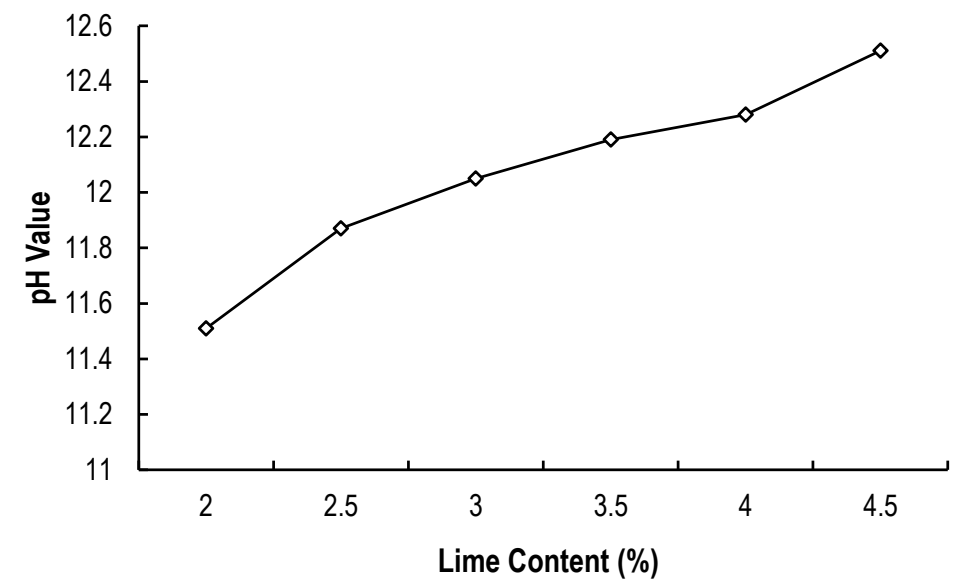

Figure 3 Eades and Grim pH Test for the ICL Determination

\subsection{Determination of Compaction Characteristics}

The strength of the stabilized samples was determined using the UCS test. However, for casting the specimens, the optimum moisture content, and the maximum dry density of the specimens needed to be determined. To simplify the testing regime, compaction characteristics were determined only for the soil samples modified with $4.5 \%$ lime, and the same compaction characteristics were adopted for all the specimens as the NA content adopted was very small. A similar methodology was adopted by other researchers [27]-[29]. The compaction test was carried out using a mini compaction apparatus, using the procedure established by Sridharan and Sivapullaiah [30] for stabilized soil, based on the BIS code IS 4332 [31]. Figure 4 shows the compaction curve for the soil sample amended with $4.5 \%$ lime. From these results of the compaction test, the maximum dry density (MDD) of the stabilized soil sample was $12.5 \mathrm{kN} / \mathrm{m}^{3}$, and the optimum moisture content (OMC) was $32.2 \%$. All of the studied specimens were prepared to have these MDD and OMC values. 


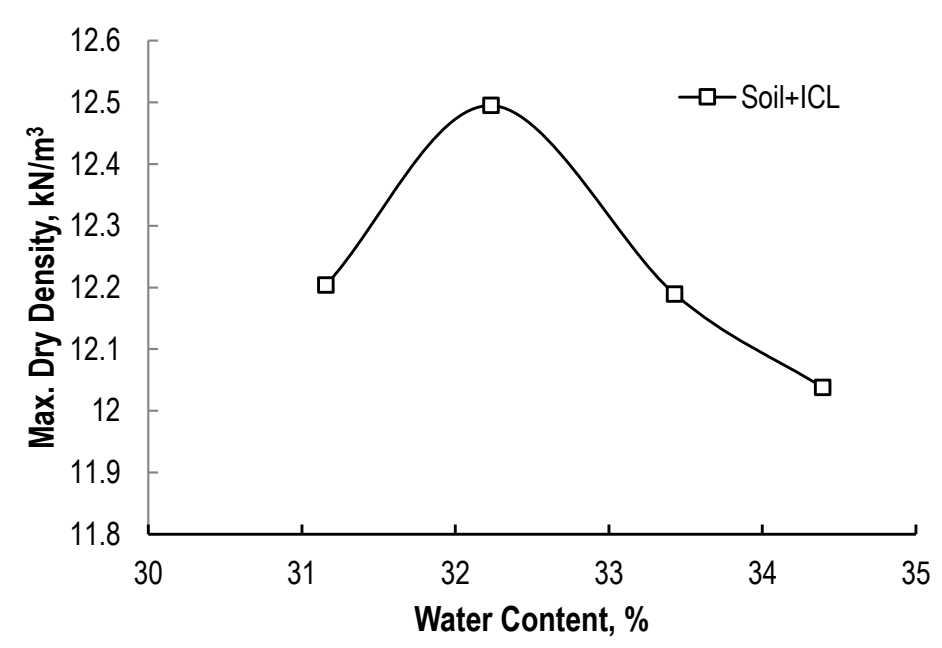

\section{Figure 4 Compaction Curve for ICL-Stabilized Soil Sample}

\subsection{Identification of Optimal NA}

Quick identification of the optimal NA content was performed using the UCS test on the specimens cured for $2 \mathrm{~h}$. Figure 5 shows the results of the UCS test, for different NA contents. Clearly, $0.5 \%$ NA yielded the maximum strength, among all of the considered NA content levels. The strength of the lime-stabilized soil samples increased from $79.2 \mathrm{kPa}$ to $135 \mathrm{kPa}$ following the addition of NA at $0.5 \%$. However, further increasing the percentage of NA tended to reduce the strength of the amended stabilized soil samples below that of the $0.5 \%$ NA-amended limestabilized soil sample. Hence, $0.5 \%$ NA was considered the optimal NA dosage for the present study. Note that the $0.5 \% \mathrm{NA}$ amendment increased the strength by approximately $70.5 \%$ after just 2-h-long curing. Thus, the optimal NA amendment can significantly enhance the immediate strength of the stabilized soil.

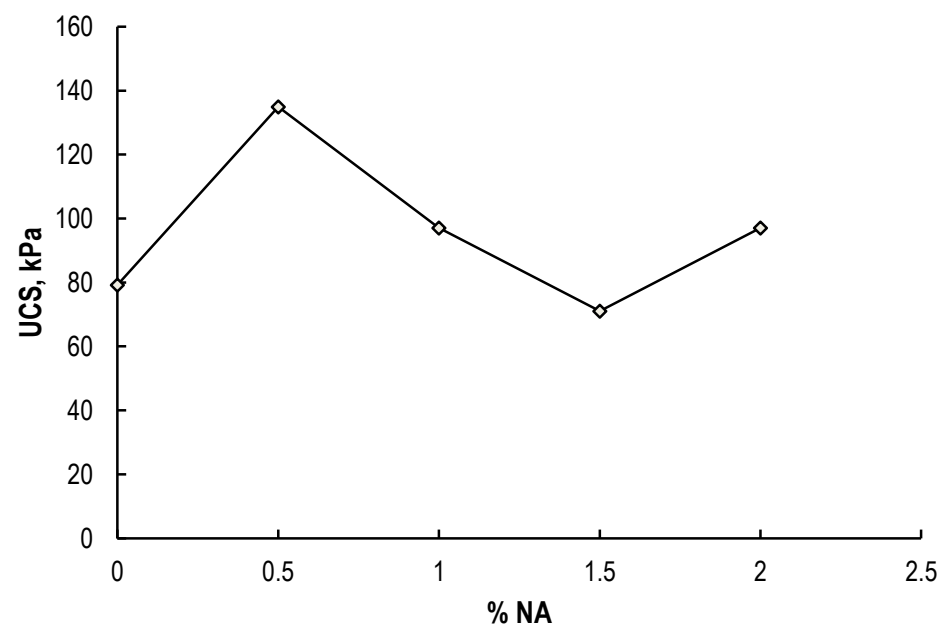

Figure 5 Determination of the Optimal NA Content

\subsection{Effect of the Curing Duration on the NA Amendment}

To understand the effect of curing on the strength development of lime-stabilized soil samples, and to confirm the long-term stability of the optimal NA content, the samples amended with different dosages of NA were cured for 
periods of 7, 14, and 28 days in sealed polythene covers. Figure 6 shows the strength of the stabilized soil during curing. At the outset, it is clear that curing increased the strength of the stabilized soil, even in the case of NAamended specimens. For all of the considered combinations, the UCS of the stabilized specimens increased from approximately $100 \mathrm{kPa}$ to more than $450 \mathrm{kPa}$. To better understand the effect of this improvement, the ratio of the strength at 28 days to that of the strength at 0 days (termed the strength gain ratio [32]), was analyzed. The minimum strength gain ratio was 4.4 , while the maximum one was 7.6 . Thus, prolonged curing is beneficial for NAamended stabilized soil specimens. Second, the trend for the $0.5 \%$ NA-amended lime-stabilized soil sample was well and clearly above the trends for the other combinations. The longer curing time also clearly confirmed that the optimal dosage of NA required for improving the soil samples' strength was in the $0.5-4.5 \%$ range for the studied lime-stabilized soil samples. It is also evident from the similarity in the trends of the strength development with the curing duration that the modification of lime stabilization with NA does not significantly alter the dependence of the strength development on the curing duration. Moreover, it can be seen that there is a very good correlation between the strength gained and the curing period for all of the currently studied combinations, as seen from the $R^{2}$ values for all the trends.

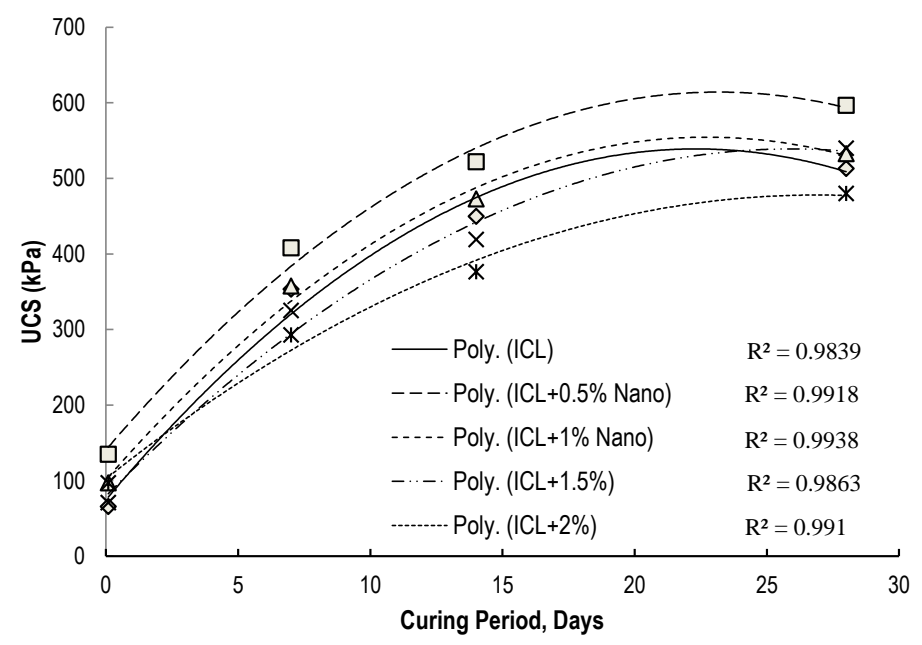

Figure 6 Effect of Curing on Strength of NA-Amended Lime-Stabilized Soil Samples

\subsection{Percentage Strength Gain Analysis}

To delve deeper into the strength development of the NA-modified lime-stabilized soil specimens, percentage strength gain analysis (Figures 7 and 8) was performed based on earlier investigations [29], [33]. Figure 7 shows the results of the percentage analysis based on additive quanta, wherein the $4.5 \%$ lime-stabilized soil sample was considered as the control sample for calculating the percentage strength gains for different curing periods. The sample with $0.5 \%$ NA exhibited a consistent percentage strength gain of approximately $15 \%$ for curing periods of 7,14 , and 28 days, whereas for the other samples there was a clear variation in their percentage strength gains. NA at $1 \%$ seems to be the next best dosage with positive strength gains across all curing periods. Although the gain for the 7-day-long curing was approximately $1 \%$, further curing improved the gain to the $3.9-5 \%$ range. The sample with NA at $1.5 \%$ exhibited a strength loss early on, but the strength gain improved until, at 28 days, the strength of the modified specimen exceeded that of the control specimen by $5.2 \%$. The sample with $2 \% \mathrm{NA}$ showed a clear strength loss across curing periods. It may be possible that any further increase in the NA content for the studied soil samples could only lead to further strength losses. More research is needed for understanding the phenomena leading to the strength loss in specimens with higher NA contents. Figure 8 shows the strength gain during the subsequent curing period. The majority of the strength gain is achieved within the 7-day-long curing, for all of the combinations. Bell [34], Nasrizar et al. [35], and James et al. [36] reported that a majority of the strength gain was achieved during the first seven days of curing for lime-treated soils. In contrast, Bhuvaneshwari et al. [33] reported such strength gain within the first three days of curing in the case of lime-treated expansive soil composites. It may be possible that if 3-day-long cured specimens had been prepared and tested, they would have revealed whether the present study agreed with the findings of Bhuvaneshwari et al. [33]. Hence, it can be seen

James, J, Sivapriya, S V, Ali, S, Madhu T R, Singh, B 
that the NA-amended lime stabilization process is more or less similar to the conventional lime stabilization process of soils.

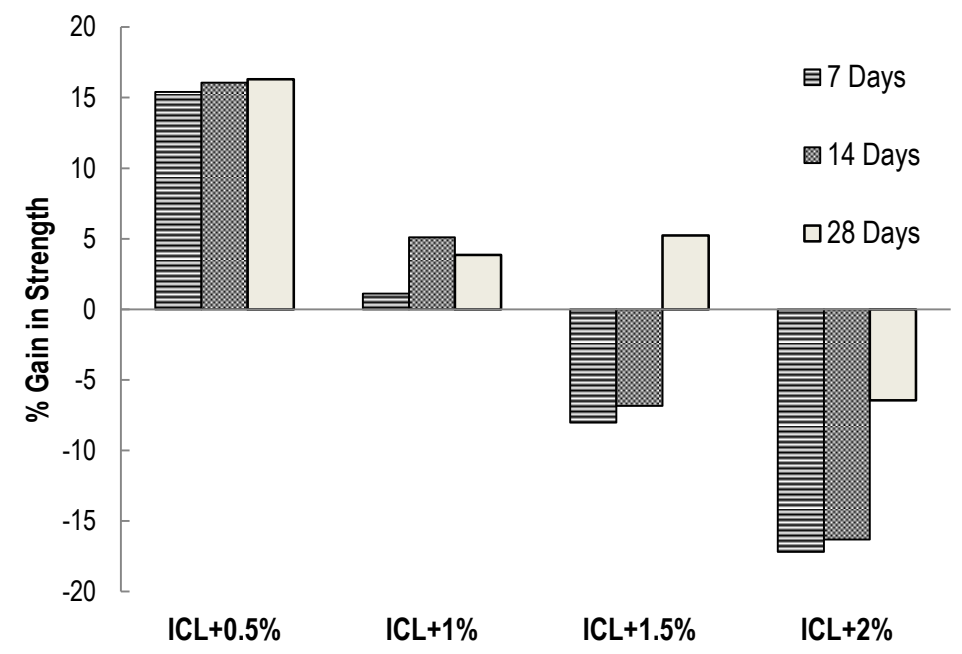

Figure 7 Percentage Strength Gain of NA-Amended Lime-Stabilized Soil Samples

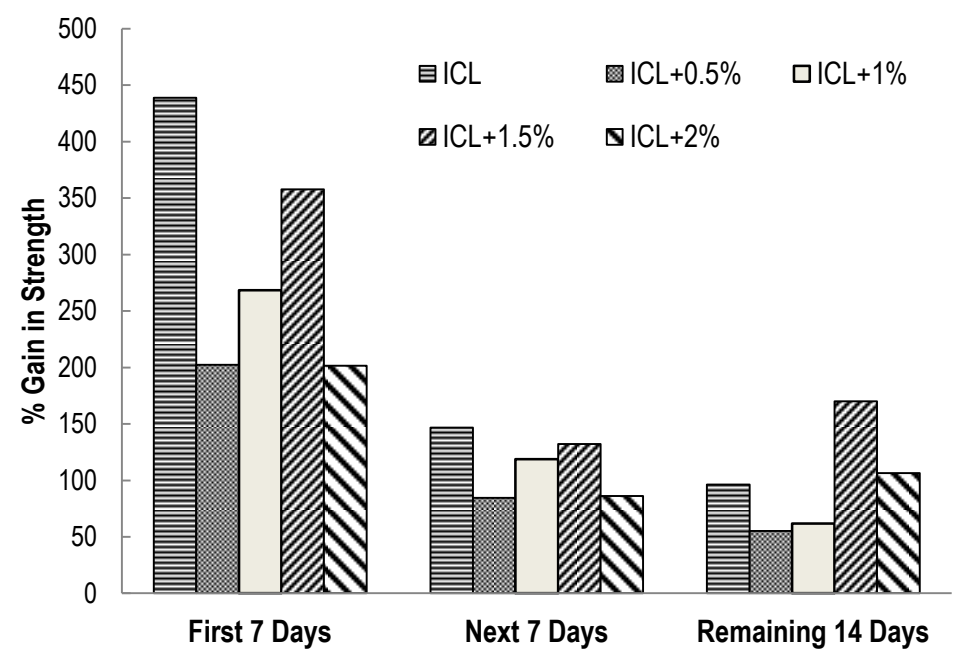

Figure 8 Percentage Strength Gain Dependence on the Subsequent Curing Period

\subsection{Durability of NA-Amended Lime-Stabilized Soil Samples}

The effect of NA on the durability of lime-stabilized soil was studied by subjecting the specimens to three and five cycles of wetting and drying. Figure 9 shows the strength of the optimal dosage of $0.5 \%$ NA-amended limestabilized soil, compared with the control specimen. Increasing the number of cycles to three, the $0.5 \% \mathrm{NA}$ amended specimen performed better, compared with the control specimen. The strength of the NA-amended specimen was $473 \mathrm{kPa}$, compared with $437 \mathrm{kPa}$ for the control specimen. After five cycles of wetting and drying, the strength of the $0.5 \%$ NA-amended specimens was comparable to that of the control specimens, although marginally less. The strength of the amended specimens was $336 \mathrm{kPa}$, compared with $344 \mathrm{kPa}$ for the control specimens. Thus, based on the durability tests on the NA-amended specimens, it can be concluded that the NA amendment does not significantly degrade the durability performance of lime-stabilized specimens, while it causes them to perform significantly better under normal conditions. 


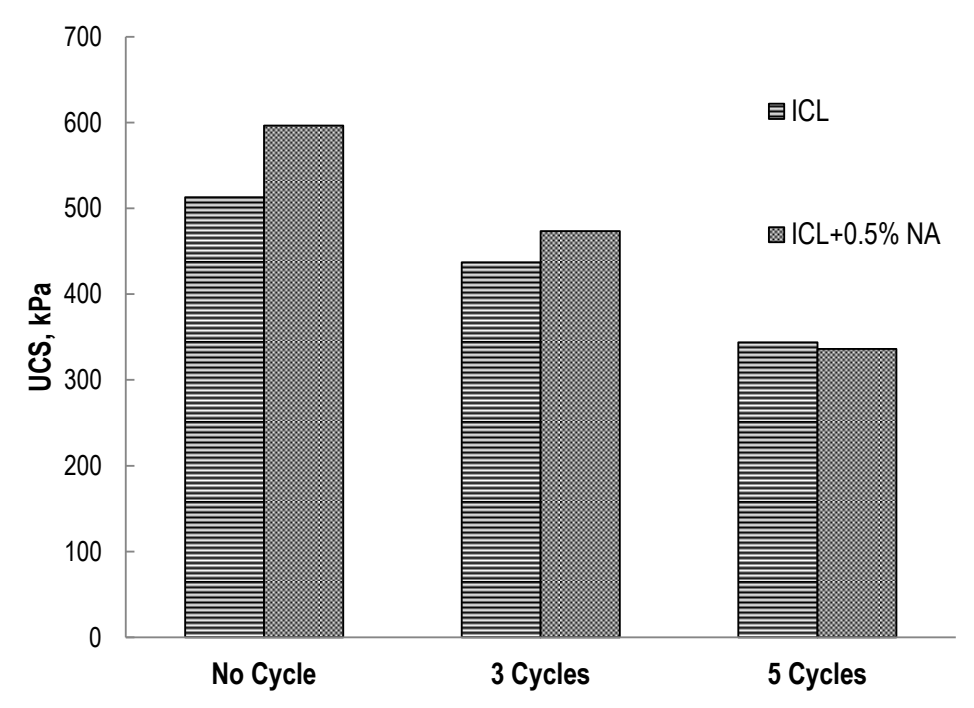

Figure 9 Durability of NA-Amended Lime-Stabilized Soil Samples

\section{CONCLUSIONS}

Expansive soils undergo large deformation upon interacting with water, and their swelling and shrinking characteristics impose an additional uplift pressure on foundations. Hence, expansive soils are typically chemically treated before construction. NA is added to these soils to increase their strength in a shorter duration. Here, an attempt was made to understand the behavior of expansive soils that were treated with lime and NA. The following conclusions were drawn based on the laboratory tests:

1. Lime plays the role of an activator in pozzolanic behavior. The minimum percentage of lime required for modifying the soil properties was $4.5 \%$. The optimal percentage of NA required to be added to the soil with ICL was $0.5 \%$. Thus, a very small amount of NA was sufficient for improving the strength gain of the stabilized soil.

2. The $0.5 \% \mathrm{NA}$ amendment resulted in the strength gain of $70.5 \%$ after $2 \mathrm{~h}$ of curing. Thus, NA amendment is very beneficial for immediately improving the strength gain of the stabilized soil. The early strength at 7 days of curing was also $15 \%$ higher than that of the pure lime-stabilized soil. A minimum gain of $15 \%$ was observed across the curing periods from 7 to 28 days, indicating that the optimal NA amendment can effectively accelerate the strength development to gain higher strength in less time.

3. Curing plays a vital role in lime stabilization. In the present study, the same can be said about lime stabilization amended with NA. With an increase in the curing period, the strength of the optimal NAamended lime-stabilized soil increased 4.4 times after 28 days of curing. The optimal NA-amended specimens were also stronger than lime-stabilized soil by $16 \%$ after 28 days of curing. Irrespective of the combination, the stabilized soils achieved a major portion of their strength at 7 days of curing, indicating a pozzolanic progression similar to that of pure lime stabilization.

4. When comparing the durability behavior of the modified soils, it was observed that the modified soils behaved significantly better under normal controlled conditions than under extreme conditions of wetting and drying. The optimal NA-amended lime-stabilized soil was better capable of resisting strength loss owing to wetting and drying of up to three cycles. However, after five cycles of wetting and drying, the performance of the optimal NA-modified lime-stabilized soil became comparable to that of conventional lime-stabilized soil. Thus, the NA amendment provided beneficial performance up to moderate durability conditions.

The present study provided insights into the effectiveness of using NA as an auxiliary additive for lime stabilization of soil. However, the mechanism behind the strength improvement needs to be understood. In future investigations, longer curing durations and advanced tests, such as X-ray diffraction and scanning electron microscopy, can be used to understand the mechanism underlying the strength gain. In addition, the performance of the NA amendment subjected to an extended number of wetting and drying cycles needs to be evaluated before

James, J, Sivapriya, S V, Ali, S, Madhu T R, Singh, B 
a concrete verdict on its performance can be given for extreme durability conditions. Other extreme conditions, such as freeze-thaw, extreme pH variations, and sulphatic soil conditions, can also be investigated.

\section{Funding}

This investigation was funded by the SSN Trust under the 'Internally Funded Student Project' Programme for the Department of Civil Engineering, Sri Sivasubramaniya Nadar College of Engineering in the academic year 20182019.

\section{Acknowledgements}

The authors would like to thank Mr. Jegadeesan, Laboratory Technician, Soil Engineering Laboratory, for helping us during the testing stage of our investigation.

\section{References}

[1] Ugwu, O.O.; Arop, J.B.; Nwoji, C.U.; Osadebe, N.N. 2013: Nanotechnology as a preventive engineering solution to highway infrastructure failures, Journal of Construction Engineering and Management, 139 (8), pp. 987-993. https://doi.org/10.1061/(ASCE)C0.1943-7862.0000670

[2] Bahmani, S. H.; Huat, B. B. K.; Asadi, A.; Farzadnia, N. 2014: Stabilization of residual soil using SiO2 nanoparticles and cement, Construction and Building Materials, 64, pp. 350-359. https://doi.org/10.1016/i.conbuildmat.2014.04.086

[3] Changizi, F.; Haddad, A. 2015: Strength properties of soft clay treated with mixture of nano-SiO2 and recycled polyester fiber, Journal of Rock Mechanics and Geotechnical Engineering, 7 (4), pp. 367-378. https://doi.org/10.1016/j.jrmge.2015.03.013

[4] Correia, A.A.S.; Casaleiro, P.D.F.; Rasteiro, M.G.B.V. 2015: Applying multiwall carbon nanotubes for soil stabilization, Procedia Engineering, 102, pp. 1766-1775. https://doi.org/10.1016/i.proeng.2015.01.313

[5] Nikookar, M.; Bahari, M.; Nikookar, H.; Arabani, M. 2013: The Strength Characteristics of Silty Soil Stabilized Using Nano-Clay, In Proceedings of 7th Symposium on Advances in Science \& Technology 7thSASTech, Bandar-Abbas, Iran, pp. 1-7.

[6] Moradi, G.; Seyedi, S. 2015: Evaluation of uniform delivery of colloidal nano-Silica stabilizer to liquefiable silty sands, International Journal of Nano Dimension, 6 (5), pp. 501-508.

[7] Correia, A.A.S.; Rasteiro, M.G. 2016: Nanotechnology Applied to Chemical Soil Stabilization, Procedia Engineering, 143, pp. 1252-1259. https://doi.org/10.1016/i.proeng.2016.06.113

[8] Wang, T.; Wang, C.; Zhang, Z.; Huang, X. 2016: Mechanical property of cement-stabilized soil with nano$\mathrm{CaO}$ and reinforcement mechanism analysis, Chemical Engineering Transactions, 51, pp. 1195-1200. https://doi.org/10.3303/CET1651200

[9] Majeed; Z.H.; Taha, M.R. 2012: Effect of nanomaterial treatment on geotechnical properties of a Penang soft soil, Journal of Asian Scientific Research, 2 (11), pp. 587-592.

[10] Choobbasti, A.J.; Vafaei, A.; Kutanaei, S.S. 2015: Mechanical properties of sandy soil improved with cement and nanosilica, Open Engineering, 5 (1), pp. 111-116. https://doi.org/10.1515/eng-2015-0011

[11] Alireza, S.G.S.; Mohammed, M.S.; Hasan, B.M. 2013: Application of Nanomaterial to Stabilize a Weak Soil, In Proceedings of 7 th international conference on case histories in geotechnical engineering, Wheeling, Illinois, USA, paper 6.10., pp. 1-8.

[12] Shahin, S.S.; Laila, P.; Fayed, A.E. 2015: Review of Nano additives in stabilization of Soil, In 7th International Conference on Nano-Technology in Construction, Sharm El-Sheikh, Egypt, pp. 1-11.

[13] Nohani, E.; Alimakan, E. 2015: The Effect of Nanoparticles on Geotechnical Properties of Clay, International Journal of Life Sciences, 9 (4), pp. 25-27. https://doi.org/10.3126/ijls.v9i4.12670

[14] BIS, IS 2720 Methods of Test for Soils: Part 5 Determination of Liquid and Plastic Limit, India, 1985, pp. 1-16.

[15] BIS, IS 2720 Methods of Test for Soils: Part 6 Determination of Shrinkage Factors, India, 1972, pp. 1-12.

[16] BIS, IS 2720 Methods of Test for Soils: Part 3 Determination of Specific Gravity/Section 1 Fine Grained Soils, India, 1980, pp. 1-8. 
[17] BIS, IS 2720 Methods of Test for Soils: Part 4 Grain Size Analysis, India, 1985, pp. 1-38.

[18] BIS, IS 2720 Methods of Test for Soils: Part 7 Determination of Water Content-Dry Density Relation Using Light Compaction, India, 1980, pp. 1-9.

[19] BIS, IS 2720 Methods of Test for Soils: Part 10 - Determination of Unconfined Compressive Strength, India, 1991, pp. 1-4.

[20] BIS, IS 1498 Classification and Identification of Soils for General Engineering Purposes, India, 1970, pp. 424.

[21] James, J.; Pandian, P.K.; Switzer, A.S. 2017: Egg Shell Ash as Auxiliary Addendum to Lime Stabilization of an Expansive Soil, The Journal of Solid Waste Technology and Management, 43 (1), pp. 15-25. https://doi.org/10.5276/JSWTM.2017.15

[22] Eades, J.L.; Grim, R.E. 1966: A Quick Test to Determine Lime Requirements for Lime Stabilization, Highway Research Record, 139, pp. 61-72.

[23] ASTM, D6276 Standard Test Method for Using pH to Estimate the Soil-Lime Proportion Requirement, vol. 14. United States, 2006, pp. 1-4.

[24] James, J.; Pandian, P.K. 2016: Geoenvironmental application of sugarcane press mud in lime stabilisation of an expansive soil: a preliminary report, Australian Journal of Civil Engineering, 14 (2), pp. 114-122. https://doi.org/10.1080/14488353.2017.1316026

[25] James, J.; Saraswathy, R. 2020: Performance of Fly Ash - Lime Stabilized Lateritic Soil Blocks Subjected to Alternate Cycles of Wetting and Drying, Civil and Environmental Engineering, 16 (1), pp. 30-38. https://doi.org/10.2478/cee-2020-0004

[26] James, J. et al. 2021: Wetting-Drying Resistance of a Lime Stabilized Soil Amended with Steel Slag and Reinforced with Fibres, ITECKNE, 18 (1), pp. 1-18. https://doi.org/10.15332/iteckne.v18i1.2490

[27] Wild, S.; Kinuthia, J.M.; Jones, G.I.; Higgins, D.D. 1998: Effects of partial substitution of lime with ground granulated blast furnace slag (GGBS) on the strength properties of lime-stabilised sulphate-bearing clay soils, Engineering Geology, 51 (1), pp. 37-53. https://doi.org/10.1016/S0013-7952(98)00039-8

[28] Bagheri, Y.; Ahmad, F.; Ismail, M.A.M. 2014: Strength and mechanical behavior of soil-cement-lime-rice husk ash (soil-CLR) mixture, Materials and Structure, 47, pp. 55-66. https://doi.org/10.1617/s11527-0130044-2

[29] James, J.; Pandian, P.K. 2018: Bagasse Ash as an Auxiliary Additive to Lime Stabilization of an Expansive Soil: Strength and Microstructural Investigation, Advances in Civil Engineering, Article ID 9658639, pp. 1-16. https://doi.org/10.1155/2018/9658639

[30] Sridharan, A.; Sivapullaiah, P. 2005: Mini compaction test apparatus for fine grained soils, Geotechnical Testing Journal, 28 (3), pp. 240-246. https://doi.org/10.1520/GTJ12542

[31] BIS, IS 4332 Methods of Test for Stabilized Soils: Part 3 Test for Determination of Moisture Density Relations for Stabilized Soil Mixtures, India, 1967, pp. 1-12.

[32] Sivapriya, S.V. 2018: Stress-strain and penetration characteristics of clay modified with crumb rubber, Revista Facultad de Ingeniería, 27 (49), pp. 65-75.

[33] Bhuvaneshwari, S.; Robinson, R.G.; Gandhi, S.R. 2014: Behaviour of Lime Treated Cured Expansive Soil Composites, Indian Geotechnical Journal, 44 (3), pp. 278-293. https://doi.org/10.1007/s40098-013-0081-3

[34] Bell, F.G. 1996: Lime stabilization of clay minerals and soils, Engineering Geology, 42 (4), pp. 223-237. https://doi.org/10.1016/0013-7952(96)00028-2

[35] Nasrizar, A.A.; Muttharam, M.; Illamparuthi, K. 2010: Role of Lime Content on Soil-Lime Reaction under Thermal Curing," In Proceedings of Indian Geotechnical Conference-2010, GEOtrendz, Mumbai, India, pp. 595-598.

[36] James, J. et al. 2018: Pozzolanic benefit of fly ash and steel slag blends in the development of uniaxial compressive strength of lime stabilized soil, Revista Facultad de Ingenieria, 27 (49), pp. 7-21.

Please cite this article as: James, J.; Sivapriya, S.V.; Ali, S.; Madhu, T.R.; Singh, B.: Wetting and Drying Resistance of Lime-Stabilized Expansive Soils Modified with Nano-Alumina, Electronic Journal of the Faculty of Civil Engineering Osijek-e-GFOS, 2021, 22, pp. 70-80, https://doi.org/10.13167/2021.22.6 